\title{
In situ cleaning of GaN(0001) surfaces in a metalorganic vapor phase epitaxy environment
}

\author{
Z. J. Reitmeier, ${ }^{\text {a) }}$ J.-S. Park, W. J. Mecouch, and R. F. Davis \\ Department of Materials Science and Engineering, North Carolina State University, Raleigh, \\ North Carolina 27695
}

(Received 29 April 2004; accepted 6 July 2004; published 23 September 2004)

\begin{abstract}
The presence of ammonia in a metalorganic vapor phase epitaxy (MOVPE) system configured for the growth of GaN films is necessary and sufficient to remove adsorbed $\mathrm{O}$ - and $\mathrm{C}$-containing species from the (0001) surface of this compound without measurable decomposition of this surface. Chemical and microstructural evidence in support of this statement has been obtained from investigations concerned with the extension of a previously developed in situ process route for cleaning heated $\mathrm{GaN}(0001)$ surfaces in a molecular beam epitaxy environment using flowing ammonia to the higher pressure regime of MOVPE. Thin films of GaN were deposited under 20 Torr total pressure on GaN templates, previously exposed to the laboratory ambient, and heated in either a nitrogen/hydrogen or an ammonia/hydrogen mixture to the deposition temperature of $1020^{\circ} \mathrm{C}$. Secondary ion mass spectroscopy of these samples revealed significant concentrations of carbon and oxygen at the $\mathrm{GaN} / \mathrm{GaN}$ interface in the former and the absence of these contaminants above the detection limits of the instrument in the latter. The surfaces of the templates heated in the nitrogen/hydrogen atmosphere also decomposed sufficiently to form a very thin liquid Ga layer that reacted with ammonia to form a GaN-containing film either at the outset of film growth or on cooling in an ammonia/nitrogen atmosphere. Atomic force microscopy (AFM) showed a smoother surface for the GaN films deposited on templates heated and cleaned in the ammonia/hydrogen mixture relative to films deposited on templates heated in the nitrogen/hydrogen mixture. The latter surface contained both a higher density of step terminations, indicative of a higher density of threading dislocations having screw and mixed character, and pits. (c) 2004 American Vacuum Society. [DOI: 10.1116/1.1786309]
\end{abstract}

\section{INTRODUCTION}

The surfaces of GaN films and GaN wafers, the latter derived, e.g., via laser liftoff, ${ }^{1}$ exposed to the ambient acquire a contamination layer containing carbon and oxygen. ${ }^{2,3}$ These impurities have a deleterious effect on the properties of films ${ }^{4}$ and of metal contacts ${ }^{5,6}$ subsequently deposited on the contaminated surface. Ex situ cleaning techniques including wet chemistry ${ }^{2}$ and ultraviolet/ozone, ${ }^{7}$ and in situ ultrahigh vacuum techniques such as nitrogen ion sputtering and vacuum annealing ${ }^{8}$ do not yield a stoichiometric GaN surface free of $\mathrm{C}$ and $\mathrm{O}$ contamination. By contrast, Tracy et al. ${ }^{9}$ achieved O- and C-free, stoichiometric (0001) surfaces of $n$ and $p$-type $\mathrm{GaN}$, within the detection limits of ultraviolet and $\mathrm{x}$-ray photoelectron spectroscopies, via in situ exposure at $860^{\circ} \mathrm{C}$ to flowing ammonia at $10^{-4}$ Torr in a gas source molecular beam epitaxy (GSMBE) system. Atomic force microscopy (AFM) and low energy electron diffraction measurements showed that the surface microstructure of these $\mathrm{GaN}$ films remained unchanged. A corresponding in situ technique for the higher pressure regimes normally employed in metalorganic vapor phase epitaxy (MOVPE) has not been reported. The advantages of such a technique would be the removal of contamination prior to (i) homoepitaxial growth on either thick pseudobulk GaN substrates or the

${ }^{a}$ Electronic mail: zach_reitmeier@ncsu.edu initial GaN template layers preceding either lateral epitaxial overgrowth ${ }^{10}$ or pendeoepitaxy ${ }^{11}$ and (ii) growth of the second nitride layer in any device requiring two growth sequences. The current investigation borrows from the process route developed by Tracy et al. ${ }^{9}$ and extends it to a MOVPE environment by incorporating flowing ammonia into the gas stream during heating to the deposition temperature of $\mathrm{GaN}$ of $1020{ }^{\circ} \mathrm{C}$. The cleaned $\mathrm{GaN}$ surface is capped with a homoepitaxial GaN film and the $\mathrm{GaN} / \mathrm{GaN}$ interface is probed via depth-profile secondary ion mass spectroscopy. The surface microstructure of the homoepitaxial films was also investigated to verify the preservation of the GaN surface during the cleaning procedure and assess the effect of different heating ambients on the microstructure of the homoepitaxial film.

\section{EXPERIMENTAL PROCEDURES}

Unintentionally doped, $1 \mu \mathrm{m}$ thick, $\mathrm{GaN}(0001)$ template layers were deposited via MOVPE on $0.1 \mu \mathrm{m}$ thick AlN buffer layers deposited in the same growth run on $6 \mathrm{H}-\mathrm{SiC}(0001)$ substrates in a vertical, resistively heated, cold wall, pancake-style system. Details regarding the growth and characterization of these layers are reported elsewhere. $^{12}$ The GaN templates were stored in Teflon ${ }^{\circledR}$-based containers. Each template surface was cleaned ex situ in a $\mathrm{HCl}: \mathrm{DIH}_{2} \mathrm{O}(1: 1)$ solution at $75^{\circ} \mathrm{C}$ for $10 \mathrm{~min}$ immediately prior to loading into the MOVPE system for 
TABLE I. Annealing conditions for GaN/AlN/SiC templates heated to $1020{ }^{\circ} \mathrm{C}$ in a MOVPE system. $\mathrm{N}_{2} / \mathrm{H}_{2}$ refers to an ambient composed of $3 \operatorname{sim~} \mathrm{N}_{2}+4 \operatorname{sim~} \mathrm{H}_{2}$. $\quad \mathrm{NH}_{3} / \mathrm{H}_{2}$ refers to an ambient composed of $3 \operatorname{sim} \mathrm{NH}_{3}+4 \operatorname{slm~} \mathrm{H}_{2}$.

\begin{tabular}{cccc}
\hline \hline Template & $\begin{array}{c}\text { Heating } \\
\text { ambient }\end{array}$ & $\begin{array}{c}\text { Anneal time } \\
\text { (min) }\end{array}$ & $\begin{array}{c}\text { Cooling } \\
\text { ambient }\end{array}$ \\
\hline A & $\mathrm{N}_{2} / \mathrm{H}_{2}$ & 0 & $\mathrm{NH}_{3} / \mathrm{H}_{2}$ \\
$B$ & $\mathrm{~N}_{2} / \mathrm{H}_{2}$ & 5 & $\mathrm{NH}_{3} / \mathrm{H}_{2}$ \\
$\mathrm{C}$ & $\mathrm{N}_{2} / \mathrm{H}_{2}$ & 0 & $\mathrm{~N}_{2} / \mathrm{H}_{2}$ \\
$D$ & $\mathrm{~N}_{2} / \mathrm{H}_{2}$ & 5 & $\mathrm{~N}_{2} / \mathrm{H}_{2}$ \\
\hline
\end{tabular}

homoepitaxial growth or annealing. Previous studies have shown that this procedure removes some contamination from the GaN surface; however, residual $\mathrm{C}$ and $\mathrm{O}$ remain. ${ }^{2}$ The chamber was then evacuated to $10^{-6}$ Torr and selected templates were heated individually at a rate of $90{ }^{\circ} \mathrm{C} / \mathrm{min}$ to $1020^{\circ} \mathrm{C}$ within different flowing ambients at a constant total pressure of 20 Torr. The ambients included (i) $3 \operatorname{slm~} \mathrm{N}_{2}+4 \operatorname{slm~} \mathrm{H}_{2}$, hereafter simplified as nitrogen/ hydrogen heating, and (ii) $3 \operatorname{sim} \mathrm{NH}_{3}+4 \operatorname{sim~} \mathrm{H}_{2}$, hereafter referred to as ammonia/hydrogen heating. An $\sim 0.25 \mu \mathrm{m}$ thick, homoepitaxial GaN film was deposited on each template. Each thin film assembly was then cooled under $3 \operatorname{sim} \mathrm{NH}_{3}+4 \operatorname{sim~} \mathrm{H}_{2}$. Selected templates were also heated, annealed, and cooled according to the parameters in Table I.

The GaN/GaN interface of the homoepitaxial films was quantitatively chemically analyzed using a Cameca $6 F$ SIMS in tandem with ion implanted GaN standards of known $\mathrm{C}$ and $\mathrm{O}$ concentration profiles. The nominal background concentrations for oxygen and carbon in this instrument are $\sim 1 \times 10^{17}$ and $\sim 3 \times 10^{17} \mathrm{~cm}^{-3}$, respectively. The surface microstructure of the annealed templates and the homoepitaxial films were determined using a Digital Instruments D3000 AFM equipped with a $\mathrm{Si}$ cantilever and tip operating in tapping mode and a JEOL 6400F field emission scanning electron microscope (SEM).

\section{RESULTS AND DISCUSSION}

\section{A. Profiles of impurity concentrations}

SIMS profiles of hydrogen, carbon and oxygen concentrations as a function of depth within two GaN film/GaN template assemblies and their associated interfaces are shown in Figs. 1(a) and 1(b). The templates on which the films were deposited were previously exposed to the laboratory ambient and then heated in the MOVPE chamber to $1020{ }^{\circ} \mathrm{C}$ in either a nitrogen/hydrogen or an ammonia/hydrogen mixture. Figure 1(a) shows marked increases in the concentrations of carbon and oxygen at a depth of $\sim 0.22 \mu \mathrm{m}$ below the sample surface. This depth corresponds well to the expected thickness of $0.25 \mu \mathrm{m}$ for the film and indicates that these species were present on the surface of the associated template prior to the initiation of the homoepitaxial growth. An increase in the hydrogen concentration at this depth was not observed.
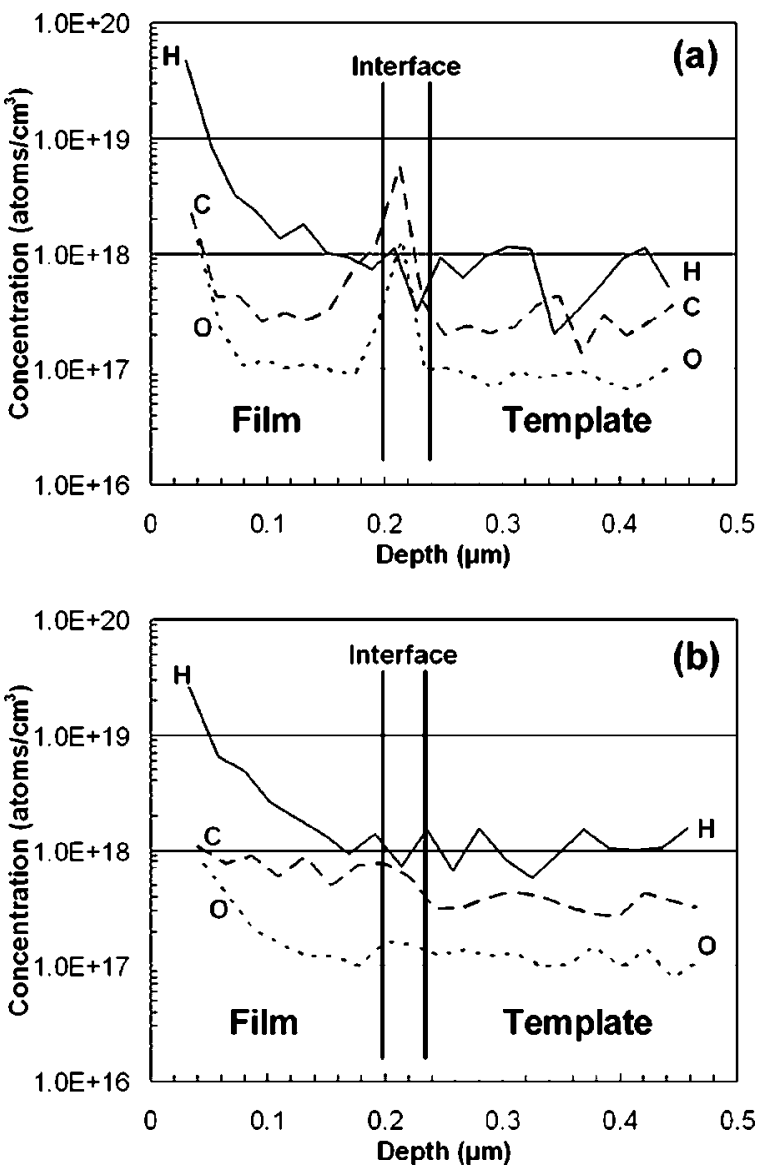

FIG. 1. SIMS depth profiles of $\mathrm{H}, \mathrm{C}$, and $\mathrm{O}$ acquired from [0001]-oriented $\mathrm{GaN}$-film/GaN-template heterostructures in which the template was heated to $1020^{\circ} \mathrm{C}$ in a mixture of either (a) nitrogen and hydrogen or (b) ammonia and hydrogen prior to the homoepitaxial growth of the films having a nominal thickness of $0.22 \mu \mathrm{m}$.

Evidence that heating the GaN template layer in ammonia results in a cleaner surface for homoepitaxy is shown in Fig. 1(b) by the essentially constant concentrations of carbon and hydrogen over most of the thickness of the sample. Additionally, these concentrations were found to be at or near the aforementioned detection limits for these species. SIMS profiles acquired from additional samples in which the GaN templates were heated in ammonia/hydrogen and held at the growth temperature for $10 \mathrm{~min}$ prior to film growth were identical to Fig. 1(b). These results show that (1) heating as-loaded $\mathrm{GaN}(0001)$ surfaces containing adsorbed $\mathrm{O}$ - and C-containing species to at least $1020{ }^{\circ} \mathrm{C}$ irrespective of the atmosphere is not sufficient to remove these species and (2) heating the same surface in the presence of ammonia is sufficient to remove these species.

The results of x-ray photoelectron spectroscopy studies by King $e t a l .^{2}$ revealed that the adsorbed oxygen- and carboncontaining species on as-loaded $\mathrm{GaN}(0001)$ surfaces exposed to a laboratory environment consisted of $\mathrm{OH}^{-}$and $\mathrm{O}^{2-}$ bonded to $\mathrm{Ga}$ and $\mathrm{C}-\mathrm{H}$ and $\mathrm{C}-\mathrm{O}$, respectively. The carbon in these species originated from the pyrolysis reaction of the triethylgallium ${ }^{13}$ and/or from the graphite heater employed in the growth reactor and/or from the hydrocarbons in the labo- 

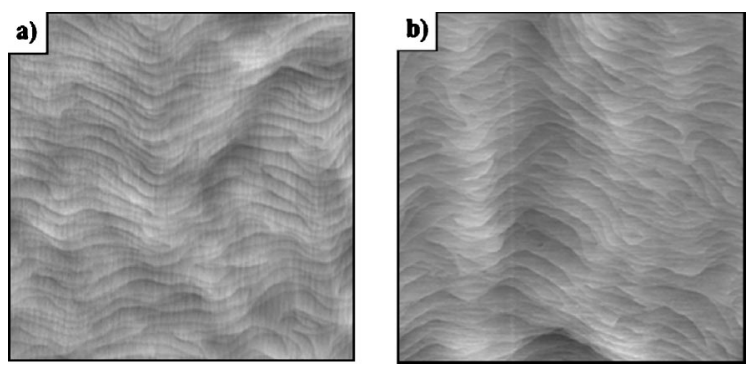

FIG. 2. AFM images acquired using $5 \times 5 \mu \mathrm{m}$ scans of the (0001) surface of a GaN template (a) before and (b) after being heated, annealed for $5 \mathrm{~min}$ and cooled in an ammonia/hydrogen atmosphere. The $Z$ range is $4 \mathrm{~nm}$ in each case.

ratory environment. Ammonia has been shown to be an excellent scavenger of hydrocarbons ${ }^{14}$ and has been observed to chemisorb dissociatively on $\mathrm{GaN}$ (0001) surfaces to form $\mathrm{NH}_{2}$ and $\mathrm{H}$ species. ${ }^{15}$ As such, the removal of the $\mathrm{C}$ - and O-containing contaminants during heating in this gas is believed to occur via reactions with the ammonia fragments and the atomic hydrogen.

A second explanation regarding the absence of contaminants at the $\mathrm{GaN} / \mathrm{GaN}$ interface is that the surface of the template layer decomposed upon heating to the growth temperature. However, ammonia has been observed to inhibit or dramatically decrease the decomposition of $\mathrm{GaN}$ as compared to heating in vacuum, hydrogen, nitrogen, or various nitrogen/hydrogen mixtures. ${ }^{16,17}$ It has been postulated that the ammonia blocks sites for $\mathrm{N}_{2}$ formation and desorption. ${ }^{18}$ To confirm or deny the preservation of the GaN surface, a template was heated, annealed for $5 \mathrm{~min}$ and cooled in our ammonia/hydrogen mixture. Representative $5 \times 5 \mu \mathrm{m}$ AFM images of the resultant surface (a) before and (b) after heating and annealing are shown in Fig. 2. The rms roughness of the respective images is 0.24 and $0.30 \mathrm{~nm}$. The images clearly reveal that the surface of a GaN template layer heated, annealed, and cooled in our ammonia/hydrogen mixture does not undergo observable decomposition. By contrast, it will be shown below that the surfaces of $\mathrm{GaN}$ templates heated to $1020^{\circ} \mathrm{C}$ in the nitrogen/hydrogen ambient do decompose. Therefore, the cleaning effect deduced from the SIMS measurements cannot be attributed to decomposition of the surface during heating.

\section{B. AFM of homoepitaxial GaN films}

Figure 3 shows $5 \times 5 \mu \mathrm{m}$ AFM images of the (0001) surfaces of the homoepitaxial GaN films deposited after heating the underlying template surfaces in (a) nitrogen/hydrogen and (b) ammonia/hydrogen. The respective rms roughness values for the two films are 1.04 and $0.36 \mathrm{~nm}$ over a $25 \mu \mathrm{m}^{2}$ area and 4.13 and $1.09 \mathrm{~nm}$ for a $400 \mu \mathrm{m}^{2}$ area. The microstructures of the surfaces of both films show that they grew via the dislocation-mediated step-flow growth mode typical of $\mathrm{GaN}$ deposited by MOVPE; ${ }^{19}$ however, there are two marked differences in these microstructures. First, the surface of the film deposited on the template heated in nitrogen/ hydrogen contained 600-800 nm diameter pits having a den-
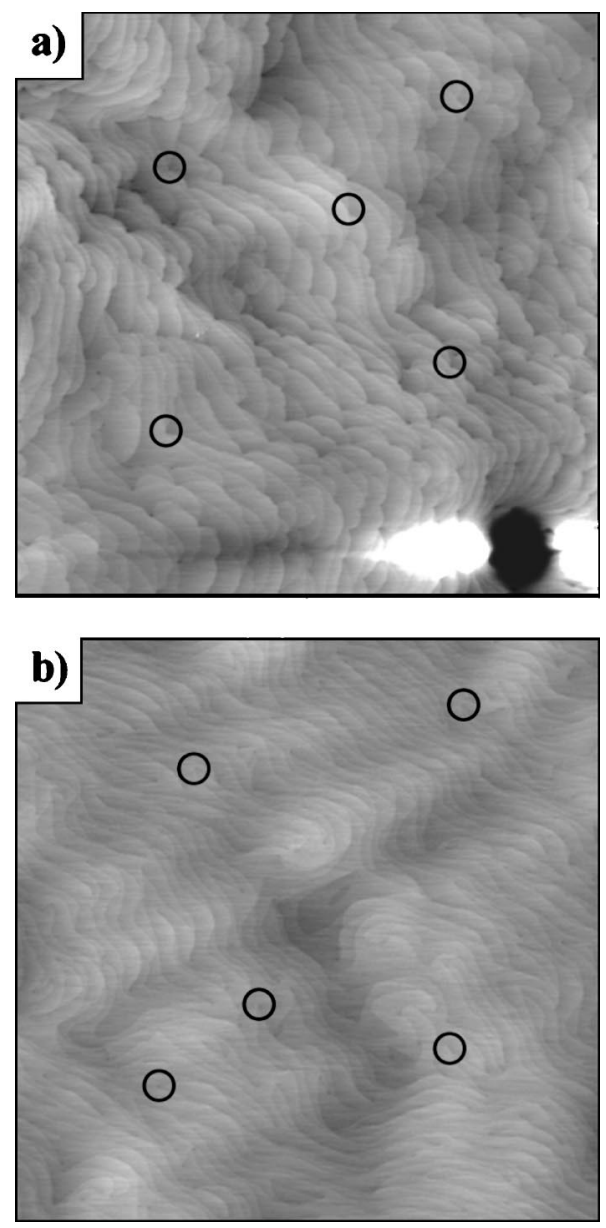

FIG. 3. AFM images acquired using $5 \times 5 \mu \mathrm{m}$ scans of the $(0001)$ surfaces of homoepitaxial GaN films deposited on $\mathrm{GaN}$ templates previously heated to $1020^{\circ} \mathrm{C}$ in (a) nitrogen and hydrogen and (b) ammonia and hydrogen. The $Z$ range is $5 \mathrm{~nm}$ in each case.

sity of $\sim 7 \times 10^{6} \mathrm{~cm}^{-2}$. An example of these pits is shown in the lower right corner of Fig. 3(a). These pits were not observed in the film deposited on the template heated in ammonia/hydrogen. Second, the surface of the film shown in Fig. 3(a) contains a larger number of step terminations that are the ends of threading dislocations having screw or mixed character ${ }^{19}$ than are observed in the film shown in Fig. 3(b). Circles in these figures surround selected terminations. Thus, the homoepitaxial film deposited on the GaN template heated in nitrogen/hydrogen contains a higher density of threading dislocations relative to the film deposited on a similar template heated in ammonia/hydrogen. Moreover, the density of step terminations in the surface of a homoepitaxial film deposited after heating the $\mathrm{GaN}$ template in ammonia and annealing for $10 \mathrm{~min}$ yielded no discernible differences relative to that observed on the surface of a film deposited on a template heated in ammonia/hydrogen without annealing. We believe that the density of these defects is correlated with the concentrations of impurities on the template surfaces. Support for this statement is found in the results of several previous studies (see, e.g., Refs. 4, 20, and 21) that have shown that the removal of contaminants from the surfaces of 

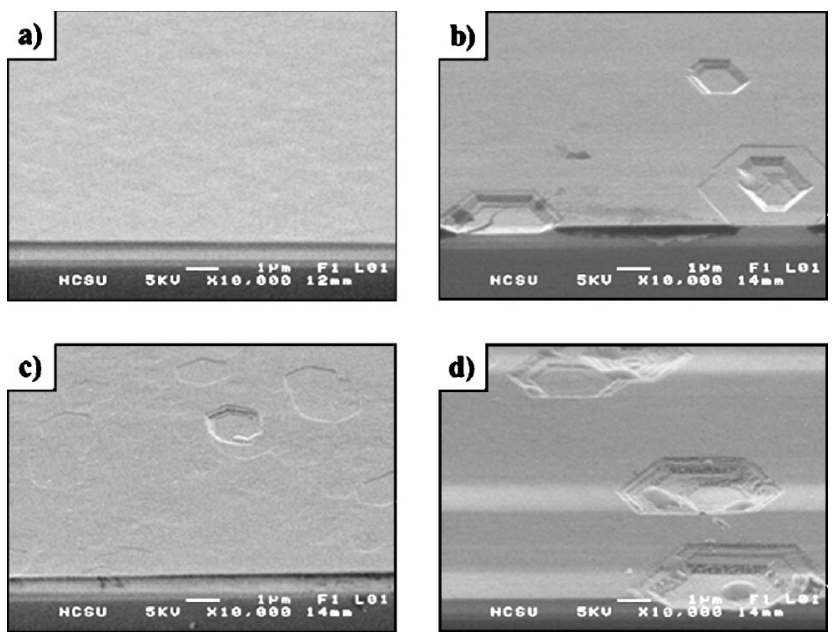

FIG. 4. SEM images showing both the surface and cross section of GaN templates subjected to the following heat treatments: (a) heating in nitrogen/ hydrogen to $1020^{\circ} \mathrm{C}$ and cooling in ammonia/hydrogen; (b) heating in nitrogen/hydrogen to $1020^{\circ} \mathrm{C}$, annealing $5 \mathrm{~min}$, and cooling in ammonia/ hydrogen; (c) heating in nitrogen/hydrogen to $1020^{\circ} \mathrm{C}$ and cooling in nitrogen/hydrogen; (d) heating in nitrogen/hydrogen to $1020^{\circ} \mathrm{C}$, annealing $5 \mathrm{~min}$, and cooling in nitrogen/hydrogen. The hexagonal pits are the result of $\mathrm{GaN}$ decomposition. Note the Ga droplets within pits shown in (d).

silicon- and gallium-arsenide-based substrates decreases markedly the concentration of growth related zero- and onedimensional defects in the subsequently deposited epitaxial films. These results correlate well with the SIMS measurements of the interfaces of similarly processed samples.

\section{SEM and AFM of GaN templates}

Previous studies by Koleske et al. $^{22}$ showed that GaN decomposes in the presence of hydrogen and nitrogen over the range of pressures employed in MOVPE. This results in the formation of $\mathrm{Ga}$ droplets on the remaining $\mathrm{GaN}$ surface, since the rate of $\mathrm{GaN}$ decomposition is greater than the rate of Ga evaporation. Additionally, they observed that the onset of measurable $\mathrm{GaN}$ decomposition occurred in the range of $800-900{ }^{\circ} \mathrm{C}$ and varied with the reactor pressure and the nitrogen/hydrogen ratio. Since the temperature for homoepitaxial growth of $\mathrm{GaN}$ in this study exceeds this temperature window for decomposition and decomposition increases exponentially with an increase in temperature, it is expected that the $\mathrm{GaN}$ surfaces of our templates decompose during heating in the nitrogen/hydrogen ambient. The effect of heating ambient and anneal time on template decomposition is shown in Figs. 4(a)-4(d) for templates A-D listed in Table I, respectively. The GaN template heated in nitrogen/hydrogen and immediately cooled in ammonia/hydrogen maintains a relatively smooth surface microstructure, comparable to that of the as-grown material, as shown in Fig. 4(a). However, annealing the template for $5 \mathrm{~min}$ in the former ambient resulted in marked decomposition that is revealed by the hexagonal pits in Fig. 4(b). A comparison of either Figs. 4(a) and 4(c) or 4(b) and 4(d) shows the effect of cooling the template in an ammonia/hydrogen ambient rather than in a nitrogen/ hydrogen ambient. Cooling under the latter results in the
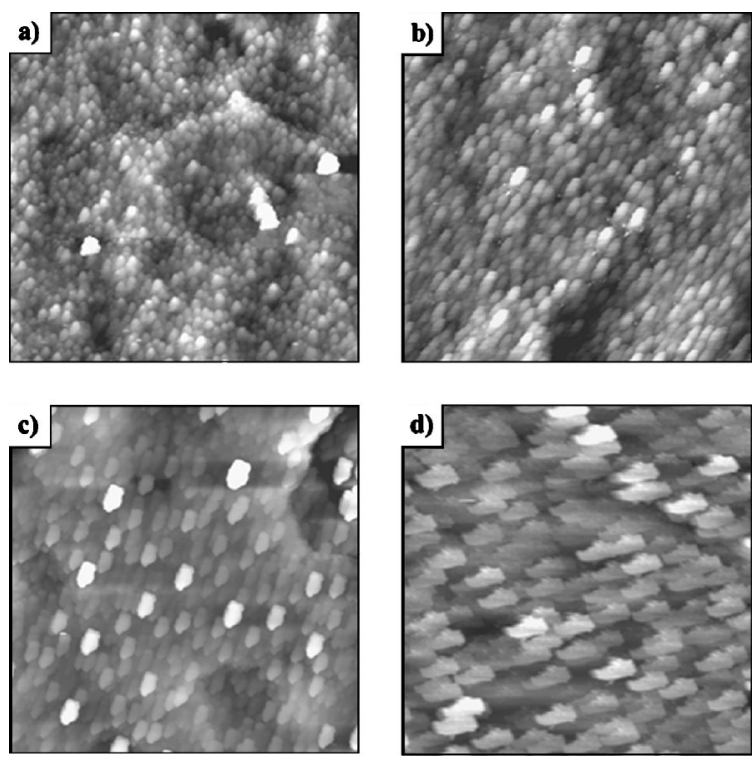

FIG. $5.5 \times 5 \mu \mathrm{m}$ AFM scans of GaN templates after (a) heating in nitrogen/ hydrogen to $1020^{\circ} \mathrm{C}$ and cooling in ammonia/hydrogen; (b) heating in nitrogen/hydrogen to $1020^{\circ} \mathrm{C}$, annealing $5 \mathrm{~min}$, and cooling in ammonia/ hydrogen; (c) heating in nitrogen/hydrogen to $1020^{\circ} \mathrm{C}$ and cooling in nitrogen/hydrogen; (d) heating in nitrogen/hydrogen to $1020^{\circ} \mathrm{C}$, annealing $5 \mathrm{~min}$, and cooling in nitrogen/hydrogen. The $Z$ ranges are 15, 15, 30, and $100 \mathrm{~nm}$ for the respective images. (a) and (b) containing layer formed via reaction of liquid Ga with ammonia; (c) and (d) show a decomposed roughened GaN surface.

continued decomposition of the template surface. The surfaces that were annealed and cooled in the absence of ammonia also contained droplets, an example of which is shown in the center of the hexagonal pit in the lower righthand corner of Fig. 4(d). Energy dispersive x-ray spectroscopy confirmed these droplets to be $\mathrm{Ga}$, in agreement with the results of Koleske et al. ${ }^{22}$ These droplets were not observed on the surfaces of the templates cooled in ammonia/ hydrogen. This provides additional, though indirect, evidence that the droplets are $\mathrm{Ga}$, since any Ga present on the surface when ammonia was introduced would have reacted to form $\mathrm{GaN}$.

Figure 5 shows $5 \times 5 \mu \mathrm{m}$ AFM images of templates A-D shown in Table I and also in the SEM images of Fig. 4. For templates in which significant decomposition occurred, the AFM images were acquired from regions between the hexagonal pits. The surfaces of the templates heated in nitrogen/ hydrogen show a much rougher microstructure, with rms roughness values of 3.09, 3.15, 3.52, and $19.0 \mathrm{~nm}$ for Figs. 5(a)-5(d), respectively, compared to the surfaces of the templates processed only in ammonia/hydrogen and shown in Fig. 2. Moreover, the former surfaces no longer exhibit the step and terrace microstructure typically observed for MOVPE-grown GaN, but instead contain numerous islands. The areas of these islands increased as the time above the decomposition temperature without the presence of ammonia increased. We propose that for templates A and B, i.e., those cooled in the ammonia/hydrogen mixture, the observed surface features are due to a thin GaN-containing layer that formed via reaction of ammonia with liquid $\mathrm{Ga}$ which was 

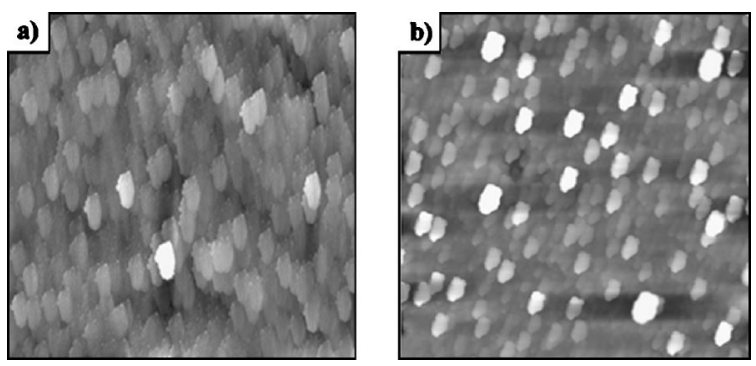

FIG. 6. $5 \times 5 \mu \mathrm{m}$ AFM scans of $\mathrm{GaN}$ templates exposed to $30 \% \mathrm{HNO}_{3}$ for $10 \mathrm{~min}$ following (a) heating in nitrogen/hydrogen to $1020^{\circ} \mathrm{C}$, annealing $5 \mathrm{~min}$, and cooling in ammonia/hydrogen; and (b) in nitrogen/hydrogen to $1020^{\circ} \mathrm{C}$ and cooling in nitrogen/hydrogen. The $Z$ ranges are 15 and $30 \mathrm{~nm}$, respectively: (a) reveals the roughened $\mathrm{GaN}$ surface after removal of the thin GaN-containing layer observed in Fig. 5(b); (b) shows that the roughened surface formed upon heating in the absence of ammonia is unaffected by exposure to $\mathrm{HNO}_{3}$.

on the surface as a result of decomposition during heating. For templates $\mathrm{C}$ and $\mathrm{D}$, i.e., those cooled in nitrogen/ hydrogen mixture, we propose that the observed surface features are roughened $\mathrm{GaN}$ as a result of decomposition of the template. We did not observe decomposition in a step-flow mode, as has been previously reported. ${ }^{22}$

To confirm that the island-like surface features observed in Figs. 5(a)-5(d) were GaN and not, for example, small Ga droplets, templates $\mathrm{B}$ and $\mathrm{C}$, which were within the window for decomposition for approximately the same time despite their different cooling ambients, were exposed to a $30 \%$ $\mathrm{HNO}_{3}$ solution for $10 \mathrm{~min}$. This solution is known to remove Ga droplets from GaN surfaces. ${ }^{22}$ Representative $5 \times 5 \mu \mathrm{m}$ AFM images of the surfaces of templates B and C after the acid dip are shown in Figs. 6(a) and 6(b), respectively. The nitric acid had a significant effect on template B [compare Fig. 6(a) with Fig. 5(b) and note the change in island size] but little-to-no effect on template $\mathrm{C}$ [compare Fig. 6(b) with Fig. 5(c)]. It is expected that if a GaN-containing layer formed on the surface of template B during cooling, it would be either polycrystalline or a two-phase mixture of $\mathrm{Ga}$ and $\mathrm{GaN}$ and thus easily removed in the $\mathrm{HNO}_{3}$ solution to reveal a surface microstructure very similar to that of template $\mathrm{C}$ prior to the exposure to the $\mathrm{HNO}_{3}$. The similarity of the microstructures of the surfaces of templates $\mathrm{B}$ and $\mathrm{C}$ after $\mathrm{HNO}_{3}$ exposure supports the hypothesis that the surface features formed during cooling in the nitrogen/hydrogen mixture are roughened $\mathrm{GaN}$ as a result of decomposition, and the features formed during cooling in ammonia are $\mathrm{GaN}$ or a mixture of $\mathrm{Ga}$ and $\mathrm{GaN}$.

Based on the evidence from Figs. 2-6, we propose the following sequences for the homoepitaxial growth on $\mathrm{GaN}$ templates after heating the latter in ammonia/hydrogen or nitrogen/hydrogen mixtures. The original step-and-terrace microstructure of the GaN surface remains unchanged when the template is heated in ammonia/hydrogen, as shown by a comparison of Figs. 2(a) and 2(b), and the carbon- and oxygen-containing species are removed from the surface via reaction with ammonia and/or ammonia fragments and hydrogen. Subsequent homoepitaxial growth occurs via step- flow mechanism, as has been previously shown for GaN deposited on $\mathrm{Al}_{x} \mathrm{Ga}_{1-x} \mathrm{~N} .{ }^{12}$ The resultant film is smooth and the contaminants are below the detection limits of SIMS at the $\mathrm{GaN} / \mathrm{GaN}$ interface. For the templates heated in nitrogen/ hydrogen, the GaN surface decomposes, leaving a thin layer of liquid $\mathrm{Ga}$ on the surface prior to the initiation of homoepitaxial growth. However, the decomposition is insufficient to remove the contaminants from the $\mathrm{GaN} / \mathrm{GaN}$ interface, as shown in the SIMS profiles in Fig. 1(a). In this latter case, the initial growth of the homoepitaxial layer consists of both the immediate reaction of ammonia with the Ga on the surface of the template, the microstructure of which should be similar to that shown in Fig. 5(a), and the homoepitaxial growth of $\mathrm{GaN}$ via the reaction of ammonia and TEG. The resultant surface microstructure of the subsequently deposited $250 \mathrm{~nm}$ GaN film still features step-flow growth but the surface is rougher and pitted, as compared to the film deposited on the template heated in ammonia/hydrogen.

\section{SUMMARY}

A previously established ammonia-based process for cleaning GaN surfaces in a high vacuum GSMBE environment has been extended to a MOVPE environment at 20 Torr. Incorporation of ammonia into the gas flow during the heating of [0001]-oriented $\mathrm{GaN}$ templates to $1020^{\circ} \mathrm{C}$ reduces the concentrations of carbon- and oxygen-containing species on this surface below the detection limits of SIMS, as shown by depth profiles through a $\mathrm{GaN}$ film/GaN template assembly. Templates heated in nitrogen/hydrogen mixtures continue to show relatively high concentrations of these contaminants at the $\mathrm{GaN} / \mathrm{GaN}$ interface. It is believed that the carbon and oxygen are removed from the surface via reaction with ammonia and/or ammonia fragments and hydrogen. AFM revealed a smoother surface microstructure for the homoepitaxial GaN films deposited after ammonia cleaning. The presence of ammonia during heating and cooling of template layers also prevents $\mathrm{GaN}$ decomposition prior to further growth. Conversely, heating the template layers in a nitrogen/hydrogen mixture results in the decomposition of the surface and the formation of a thin layer of $\mathrm{Ga}$. The surfaces of homoepitaxial films grown on GaN templates heated in the absence of ammonia contained both pits and a higher density of step terminations. This rougher surface microstructure is a consequence of the reaction between the liquid $\mathrm{Ga}$ and ammonia to form a thin GaN-containing layer on the surface of the template at the outset of homoepitaxial growth. The higher density of step terminations is indicative of a higher density of threading dislocations having screw and mixed character.

\section{ACKNOWLEDGMENTS}

This research was funded by the Office of Naval Research via Contract No. N00014-01-1-0729 (C. Wood, Monitor). One of the authors (R.F.D.) was partially supported by the Kobe Steel, Ltd. Professorship. Z.J.R. acknowledges financial support from the U.S. Department of Education G.A.A.N.N Electronic Materials Fellowship. 
${ }^{1}$ T. Paskova, V. Darakchieva, P. Paskov, U. Sodervall, and B. Monemar, J. Cryst. Growth 246, 207 (2002).

${ }^{2}$ S. W. King, J. P. Barnak, M. D. Bremser, K. M. Tracy, C. Ronning, R. F. Davis, and R. J. Nemanich, J. Appl. Phys. 84, 5248 (1998).

${ }^{3}$ K. Prabhakaran, T. G. Andersson, and K. Nozawa, Appl. Phys. Lett. 69, 3212 (1996)

${ }^{4}$ C. M. Rouleau and R. M. Park, J. Appl. Phys. 73, 4610 (1993).

${ }^{5}$ Q. Z. Liu, S. S. Lau, N. R. Perkins, and T. F. Kuech, Appl. Phys. Lett. 69, 1722 (1996).

${ }^{6}$ P. J. Hartlieb, A. M. Roskowski, R. F. Davis, and R. J. Nemanich, J. Appl. Phys. 91, 9151 (2002).

${ }^{7}$ K. N. Lee, S. M. Donovan, B. Gila, M. Overberg, J. D. Mackenzie, C. R. Abernathy, and R. G. Wilson, J. Electrochem. Soc. 147, 3087 (2000).

${ }^{8}$ R. W. Hunt, L. Vanzetti, T. Castro, K. M. Chen, L. Sorba, P. I. Cohen, W. Gladfelter, J. M. van Hove, J. N. Kuznia, M. A. Khan, and A. Franciosi, Physica B 185, 415 (1993).

${ }^{9}$ K. M. Tracy, W. J. Mecouch, R. F. Davis, and R. J. Nemanich, J. Appl. Phys. 94, 3163 (2003).

${ }^{10} \mathrm{~B}$. Beaumont, Ph. Vennéguès, and P. Gibart, Phys. Status Solidi B 227, 1 (2001).

${ }^{11}$ A. M. Roskowski, E. A. Preble, S. Einfeldt, P. M. Miraglia, J. Schuck, R.
Grober, and R. F. Davis, Opto-Electron. Rev. 10, 261 (2002).

${ }^{12}$ S. Einfeldt, Z. J. Reitmeier, and R. F. Davis, J. Cryst. Growth 253, 129 (2003).

${ }^{13}$ O. Ambacher, M. S. Brandt, R. Dimitrov, T. Metzger, M. Stutzman, R. A. Fisher, A. Miehr, A. Bergmaier, and G. Dollinger, J. Vac. Sci. Technol. B 14, 3532 (1996).

${ }^{14}$ F. C. Sauls, W. J. Hurley, L. V. Interrante, P. S. Marchetti, and G. E. Maciel, Chem. Mater. 7, 1361 (1995).

${ }^{15}$ V. M. Bermudez, Chem. Phys. Lett. 317, 290 (2000).

${ }^{16}$ A. Rebey, T. Boufaden, and B. El Jani, J. Cryst. Growth 203, 12 (1999).

${ }^{17}$ D. D. Koleske, A. E. Wickenden, and R. L. Henry, MRS Internet J. Nitride Semicond. Res. 5S1, W3.64 (2000).

${ }^{18}$ N. Grandjean, J. Massies, F. Semond, S. Yu Karpov, and R. A. Talalaev, Appl. Phys. Lett. 74, 1854 (1999).

${ }^{19}$ B. Heying, E. J. Tarsa, C. R. Elsass, P. Fini, S. P. DenBaars, and J. S. Speck, J. Appl. Phys. 85, 6470 (1999).

${ }^{20}$ R. P. Vasquez, B. F. Lewis, and F. J. Grunthaner, Appl. Phys. Lett. 42, 293 (1983).

${ }^{21}$ M. Yamada and Y. Ide, Jpn. J. Appl. Phys., Part 2 33, L671 (1994).

${ }^{22}$ D. D. Koleske, A. E. Wickenden, R. L. Henry, J. C. Culbertson, and M. E. Twigg, J. Cryst. Growth 223, 466 (2001). 